
К. ЛЭЭТС

\title{
СИНТЕЗ НЕКОТОРЫХ ГИДРОКСИ- И НЕНАСЫЩЕННЫХ АЛИФАТИЧЕСКИХ НИТРИЛОВ
}

$\alpha, \beta$-Ненасыщенные нитрилы представляют интерес как исходное сырье для синтеза биологически активных и душистых веществ, а также полимеров. В настоящей работе проверялась возможность получения 3-метил-2-бутенонитрила (I) и 3-метил-2-пентенонитрила (II) альдольной конденсацией ацетонитрила и соответствующего карбонильного соединения:

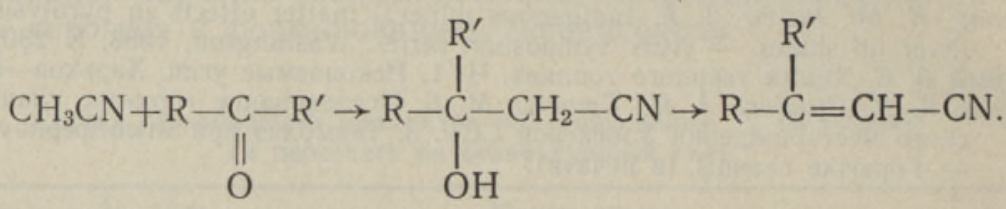

В литературе приведены данные реакции ацетонитрила с некоторыми карбонильными соединениями, в том числе с ацетоном и бутаноном. В качестве катализаторов использованы сильные основания $\mathrm{NaNH}_{2}$, $\mathrm{LiNH}_{2}\left[{ }^{1}\right]$ и $\left[\left(\mathrm{CH}_{3}\right)_{2} \mathrm{CH}\right]_{2} \mathrm{NLi}\left[{ }^{2}\right]$. Выделены $\beta$-гидроксинитрилы, в том числе 3-гидрокси-3-метилбутанонитрил (III) и 3-гидрокси-3-метилпентанонитрил (IV).

Запатентован метод, приводящий к получению $\alpha, \beta$-ненасыщенных нитрилов. Согласно ему, реакция ацетонитрила с алифатическими метилкетонами ( $\mathrm{C}_{9}$ и выше) проводима в присутствии гидроксидов щелочных металлов, гидроксида бария нли четвертичных аммониевых оснований. Заявлено о возможности проведения процесса с избытком ацетонитрила в широких пределах температуры $\left(20-200{ }^{\circ} \mathrm{C}\right)$ и концентрации гидроксида $(0,01-10$ экв.). Практические синтезы проведены в основном в условиях длительного нагревания ацетонитрила, кетона и гидроксида $(10: 1: 1)$ при $50-125^{\circ} \mathrm{C}\left[{ }^{3}\right]$. Возможности указанного синтеза $\alpha$, $\beta$-ненасыщенных нитрилов уточнены дальнейшими исследованиями [ $\left.{ }^{4-6}\right]$. Осуществлены реакции ацетонитрила с алициклическими, ароматическими и некоторыми алифатическими кетонами $\left(\mathrm{C}_{5}, \mathrm{C}_{7}, \mathrm{C}_{9}\right)$, а также с ароматическими альдегидами. Процесс проведен преимущественно при нагревании ацетонитрила, карбонильного соединения и гидроксида (до $20: 1: 1$ ) при $83 \pm 3{ }^{\circ} \mathrm{C}$ в течение от нескольких минут до 10 ч ${ }^{[5,6]}$. Как и ранее [3], наивысшие выходы ненасыщенных нитрилов получены при использовании $\mathrm{KOH}$, а с $\mathrm{NaOH}$ значительно ниже [ $\left.{ }^{6}\right]$. Одновременно указано на невоспроизводимость примеров вышеописанного патента [5]. Отмечено, что данный метод получения $\alpha$, $\beta$-ненасыщенных нитрилов непригоден в случаях, когда температура кипения исходного кетона ниже температуры кипения ацетонитрила, а также в случае алифатических альдегидов вследствие их быстрой самоконденсации [ $\left.{ }^{6}\right]$.

\section{Результаты}

Нами проведены реакции ацетонитрила с ацетоном соответственно методике получения $\alpha, \beta$-ненасыщенных нитрилов [3,6]. Нагревая ацето- 
нитрил, ацетон и измельченный $\mathrm{KOH}(10: 1: 1) 5$ ч при $50{ }^{\circ} \mathrm{C}$ получили $\mathrm{I}$ с выходом $13 \%$. При использовании в качестве основания $\mathrm{NaOH}$, $\mathrm{Ba}(\mathrm{OH})_{2}$ или $\mathrm{CH}_{3} \mathrm{ONa}$ целевого продукта не получали.

Смешивание ацетонитрила, ацетона и $\mathrm{KOH}$ при комнатной температуре сопровождалось экзотермической реакцией с выделением объемистого осадка. Гидролиз последнего давал гидроксинитрил III (доказано методом ЯМР). В табл. 1 приведены результаты получения III в различных условиях. Изучению подвергались природа гидроксида, метод его измельчения, время смешивания, температура и соотношение реагентов. Продукт реакции обрабатывали водой до растворения осадка, что привело к расслоению и возможности выделения III в виде раствора в ацетонитриле. Выход III вычисляли по данным ГЖХ перегнанного продукта.

Выявленные оптимальные условия синтеза III оказались пригодными для получения гидроксинитрила IV из ацетонитрила и бутанона (выход $\sim 40 \%$ ).

Была изучена также возможность присоединения ацетонитрила к низшим алифатическим альдегидам. Продуктов присоединения с этаналем, пропаналем и бутаналем получить не удалось, хотя во избежание самоконденсации данные альдегиды добавляли очень медленно к реакционной массе. Однако с 2-метилпропаналем образовался 3-гидрокси-4-метилпентанонитрил (V) с выходом выше $60 \%$.

Поскольку целью работы был синтез $\alpha, \beta$-ненасыщенных нитрилов, то в последующем изучали реакцию дегидратации синтезированных гидроксинитрилов. Для выяснения оптимальных условий дегидратации нитрила III до I проверяли метод дегидратации гидроксинитрилов действием $\mathrm{H}_{2} \mathrm{SO}_{4}$ или $\mathrm{H}_{3} \mathrm{PO}_{3}\left[{ }^{7}\right]$. При перегонке III с кислотой получали смесь I с 3-метил-3-бутенонитрилом (VI) (соотношение $1: 0,3-0,5)$ с выходом $30-50 \%$. Другие обычно применяемые дегидратирующие агенты $\left(\mathrm{P}_{2} \mathrm{O}_{5}\right.$,

Таблица 1

Реакция ацетонитрила с ацетоном

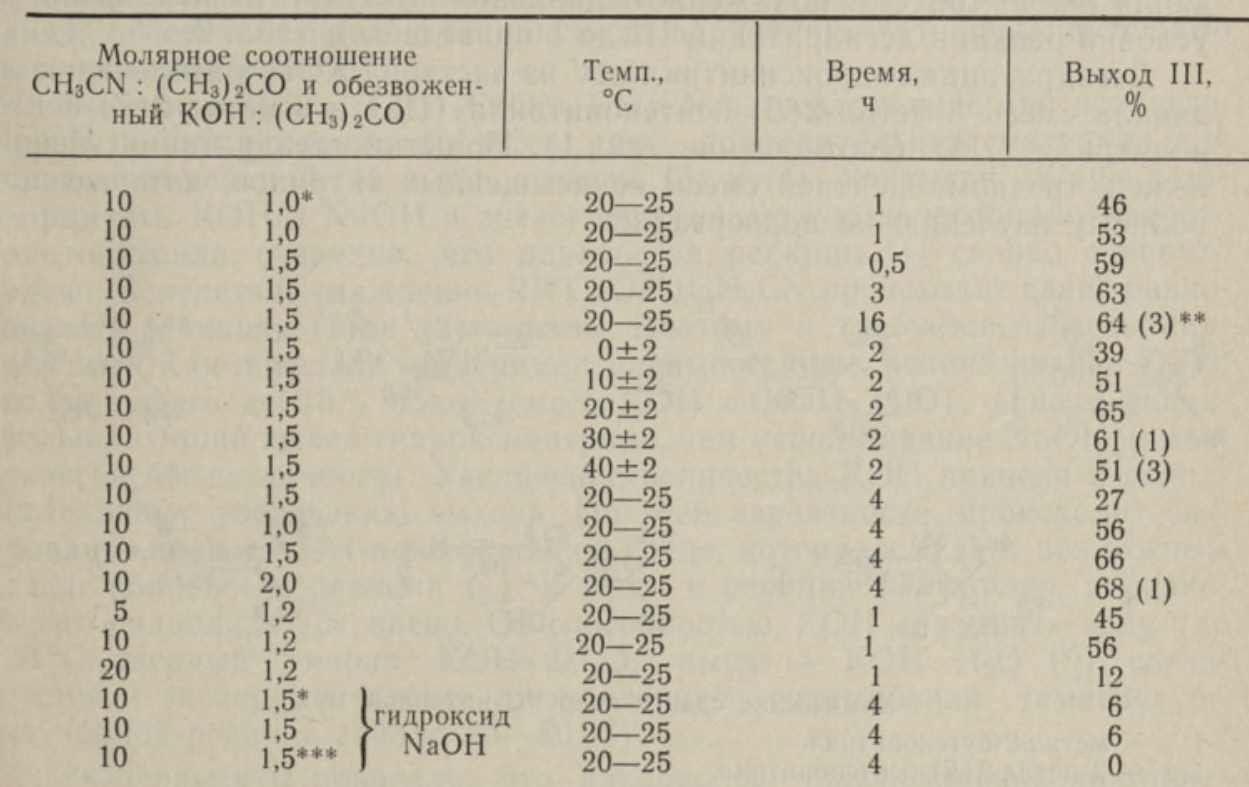

* Гидроксид измельчен на воздухе, в остальных случаях в ацетонитриле.

** В скобках выход побочного I, в остальных случаях выход I $<1 \%$.

*** $85 \% \mathrm{NaOH}+15 \% \mathrm{H}_{2} \mathrm{O}$. 
Дегидратация 3-гидрокси-3-метилбутанонитрила (III) до 3-метил-2-бутенонитрила (I)

\begin{tabular}{|c|c|c|c|c|}
\hline \multicolumn{2}{|c|}{$\begin{array}{c}\text { Молярное соотношение } \\
\text { этиленгликоль : обезвоженный } \\
\text { КОН и III : обезвоженный КОН }\end{array}$} & $\begin{array}{l}\text { Темп., } \\
\pm 10^{\circ} \mathrm{C}\end{array}$ & $\begin{array}{l}\text { Давление, } \\
\text { мм рт. ст. }\end{array}$ & $\begin{array}{c}\text { Выход I, } \\
\%\end{array}$ \\
\hline $\begin{array}{r}40 \\
40 \\
40 \\
110 \\
40 \\
20 \\
5 \\
40 \\
40 \\
70^{*} \\
5^{* *} \\
60^{* *}\end{array}$ & $\begin{array}{c}60 \\
60 \\
60 \\
60 \\
60 \\
60 \\
60 \\
100 \\
30 \\
40 \\
40^{* *} \\
24^{* *}\end{array}$ & $\begin{array}{r}140 \\
100 \\
60 \\
100 \\
100 \\
100 \\
100 \\
100 \\
100 \\
100 \\
100 \\
100\end{array}$ & $\begin{array}{l}760 \\
150 \\
100 \\
150 \\
150 \\
150 \\
150 \\
150 \\
150 \\
150 \\
150 \\
150\end{array}$ & $\begin{array}{l}55 \\
58 \\
56 \\
81 \\
69 \\
68 \\
66 \\
76 \\
67 \\
73 \\
72 \\
83\end{array}$ \\
\hline
\end{tabular}

* КОН в глицерине.

** $\mathrm{NaOH}$ в этиленгликоле.

$\mathrm{CH}_{3} \mathrm{C}_{6} \mathrm{H}_{4} \mathrm{SO}_{2} \mathrm{OH}, \mathrm{ZnCl}_{2}$ ) привели также к образованию смесей I и $\mathrm{VI}$ c низкими выходами.

Так как по вышеприведенным одностадийным методам получения ненасыщенных нитрилов $\left[^{3-6}\right]$ дегидратация гидроксинитрилов протекает под действием основания, нами изучалось действие $\mathrm{KOH}$ и $\mathrm{NaOH}$ (при $80-100^{\circ} \mathrm{C}$ ), а также $\mathrm{K}_{2} \mathrm{CO}_{3}$ (при $150^{\circ} \mathrm{C}$ ) на III. Установили образование в основном продуктов деструкции - ацетона и ацетонитрила. Выход нитрила I составил всего 12,22 и $26 \%$ соответственно. Удовлетворительные выходы I удавалось получать при быстром удалении продуктов дегидратации гидроксинитрила из растворов $\mathrm{KOH}$ или $\mathrm{NaOH}$ в высококипящем полярном растворителе (этиленгликоль, глицерин) при нагревании около $100^{\circ} \mathrm{C}$ и пониженном давлении. Результаты варьирования условий реакции дегидратации III до I приведены в табл. 2.

Дегидратация гидроксинитрила IV из раствора КОН в этиленгликоле давала смесь 3-метил-2 $(E)$-пентенонитрила (IIa) и 3-метил-2 $(Z)$-пентенонитрила (ІІб) (соотношение $\sim 2: 1$ ). Попытки дегидратации V привели к трехкомпонентной смеси ненасыщенных нитрилов, которые подробному изучению не подвергались.
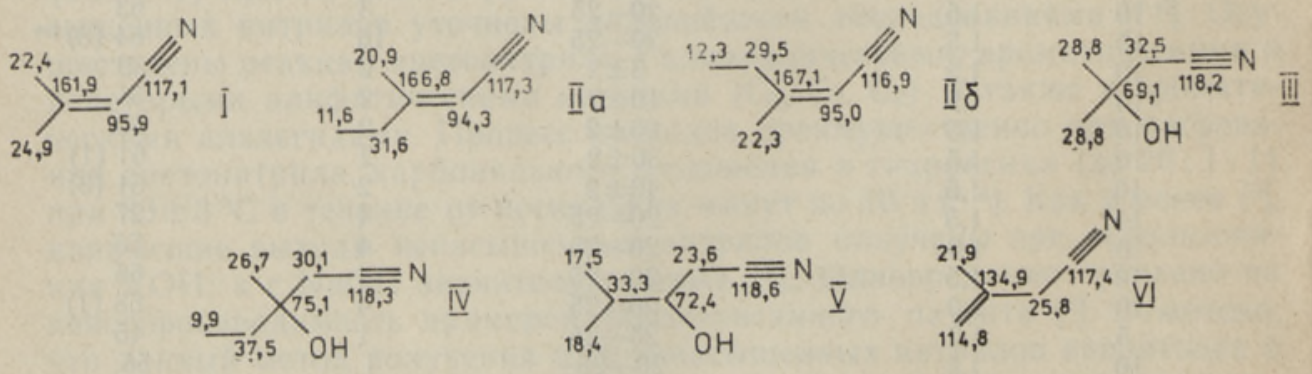

Химические сдвиги ядер ${ }^{13} \mathrm{C}$ нитрилов, м. д.:

I - метил-2-бутенонитрил,

IІа - 3-метил-2 $(E)$-пентенонитрил,

IIб - 3-метил-2(Z) -пентенонитрил,

III - 3-гидрокси-3-метилбутанонитрил,

IV - 3-гидрокси-3-метилпентанонитрил,

$\mathrm{V}$ - 3-гидрокси-4-метилпентанонитрил,

VI - 3-метил-3-бутенонитрил. 
Для установления химического строения продуктов использовали методы ИК- и ${ }^{13} \mathrm{C}$-ЯМР-спектроскопии (см. рисунок). Анализы изомеров Iа и ІІб проводили в их смеси, а VI в смеси с I. В литературе приведены наряду с данными ИК-спектроскопии и данные ${ }^{13} \mathrm{C}$-ЯМР-спектроскопии по I и VI [ $\left.{ }^{8}\right]$, с которыми полученные нами результаты хорошо согласуются.

\section{Обсуждение результатов}

На основе вышеизложенных экспериментальных, а также литературных данных можно представить процесс получения ненасыщенных нитрилов в следующем виде:

где $\mathrm{M}=\mathrm{K}, \mathrm{Na}$,

$$
\mathrm{CH}_{3} \mathrm{CN}+\mathrm{MOH} \rightleftarrows \stackrel{\oplus}{\mathrm{M}} \stackrel{\ominus}{\mathrm{C}} \mathrm{H}_{2} \mathrm{CN}+\mathrm{H}_{2} \mathrm{O}
$$

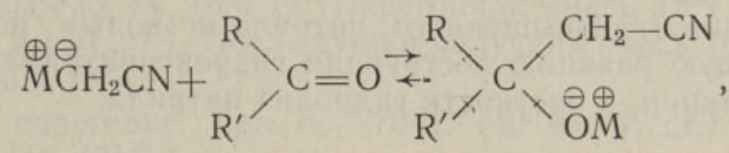<smiles>[R]C([R])([R])CC#N</smiles><smiles></smiles>

Реакции (1)-(3) обратимы. Равновесие конденсационных реакций ацетонитрила с карбонильными соединениями сдвинуто вправо в условиях, обеспечивающих постоянную дегидратацию (4) промежуточного $\beta$-гидроксинитрила $\left[{ }^{3-6}\right]$.

Факт выделения $\left(\mathrm{CH}_{3}\right){ }_{2} \mathrm{C}(\mathrm{OM}) \mathrm{CH}_{2} \mathrm{CN}$ в твердом виде при использованных нами условиях процесса дает дополнительный материал для трактовки реакций (1) и (2), а также (3) и (4). Учитывая низкую растворимость $\mathrm{KOH}$ и $\mathrm{NaOH}$ в ацетонитриле и малую депротонированность ацетонитрила, очевидно, что равновесие реакции (1) сильно сдвинуто влево. Вследствие осаждения $\mathrm{RR}^{\prime} \mathrm{C}(\mathrm{OM}) \mathrm{CH}_{2} \mathrm{CN}$ происходит сдвиг равновесия в реакциях (1) и (2) вправо. Поэтому и требуется избыток гидроксида. Қак показали экспериментальные данные, использование КОН, содержащего до $15 \%$ воды (смесь $\mathrm{KOH} \mathrm{c} \mathrm{KOH} \cdot \mathrm{H}_{2} \mathrm{O}$ ), давало значительно лучший выход гидроксинитрила, чем использование $\mathrm{NaOH}$ (практически обезвоженного). Увеличение количества КОН привело к дополнительному увеличению выхода. По всей вероятности, происходит связывание воды с $\mathrm{KOH}$ в реакционной среде, которое и делает возможным сдвиг равновесия реакции (1), а затем и реакции (2) вправо, а равновесия гидролиза (3) влево. Со способностью $\mathrm{KOH}$ связывать воду (до $33^{\circ} \mathrm{C}$ твердый гидрат $\mathrm{KOH} \cdot 2 \mathrm{H}_{2} \mathrm{O}$, выше $-\mathrm{KOH} \cdot \mathrm{H}_{2} \mathrm{O}$ [ $\left.{ }^{9}\right]$ ) согласуется и экспериментально установленная оптимальная температура изучаемой реакции (около $20-30^{\circ} \mathrm{C}$ ).

Эксперименты показали, что альдольное присоединение ацетонитрила к карбонильному соединению протекает по-разному в зависимости от того, является ли последним кетон или различные альдегиды. Получение хорошего выхода гидроксинитрила V указывает на возможные электронные эффекты в молекуле 2-метилпропаналя, отличающие по- 
следний от незамещенных альдегидов и препятствующие реакции самоконденсации альдегида.

По вышеприведенной схеме обсуждаемого процесса, за реакцией образования RR' $\mathrm{R}(\mathrm{OM}) \mathrm{CH}_{2} \mathrm{CN}$ следует реакция гидролиза (3), который протекает легко при обработке алкоголята водой. Результат подтверждает предположение о сильном смещении равновесия реакции (3) вправо при избытке воды и при комнатной температуре.

Очевидно, что реакция дегидратации (4) протекает по-разному из-за разного механизма действия кислотных и щелочных агентов. На это указывает получение смеси изомерных ненасыщенных нитрилов I и VI при кислотной и чистой I при щелочной дегидратации гидроксинитрила III. Реакции дегидратации (4) (как кислотной, так и щелочной) способствует повышение температуры. Однако при повышенных температурах, в присутствии больших,количеств щелочи и вследствие летучести карбонильного соединения равновесие реакций (1)-(3) сдвигается влево. Применение для дегидратации (4) по возможности малых концентращий щелочи в растворителе, а также быстрая отгонка продуктов дегидратации (ненасыщенного нитрила и воды) позволяют подавить параллельную реакцию деструкции гидроксинитрила и возможные побочные реакции, в частности гидролиз нитрила.

\section{Экспериментальная часть}

ГЖХ анализ проводили на хроматографе «Хром-5» с ПИД, стеклянная колонка $24000 \times 0,3$ мм, жидкая фаза 1,2,3-три (2-цианоэтокси) пропан, температура испарителя $230^{\circ} \mathrm{C}$, термостата $90^{\circ} \mathrm{C}$, скорость газаносителя (аргона) 2,5 мл/мин.

ИК-спектры снимали на приборе «Specord UR-20».

Спектры ЯMP ${ }^{13} \mathrm{C}$ снимали на спектрометре «Bruker» CXP-360 (ФРГ) (90,55 МГц) в растворе $\mathrm{CDCl}_{3}$, внутренний стандарт - тетраметилсилан.

3-Гидрокси-3-метилбутанонитрил (III). Таблетки $85 \%$ KOH (19,8 г) измельчали в ацетонитриле $(82$ г), и смесь переводили в трехгорлую колбу. При перемешивании смеси и охлаждении в колбу добавляли ацетон $\left(11,6\right.$ г). Перемешивание продолжали при $20-25^{\circ} \mathrm{C}$ в течение 4 ч. Затем добавляли воду (40 мл) до растворения осадка и отделяли слои в делительной воронке. Водный раствор экстрагировали ацетонитрилом $\left(2 \times 10\right.$ мл). Ацетонитрильный раствор нейтрализовали, добавляя $\mathrm{H}_{2} \mathrm{SO}_{4}$, промывали насыщенным водным раствором $\mathrm{K}_{2} \mathrm{CO}_{3}(3 \times 20$ мл) и высушивали над $\mathrm{MgSO}_{4}$. После отгонки ацетонитрила перегоняли III $(12,6$ г) при $120-125^{\circ} \mathrm{C}$ (45 мм рт. ст.), чистота $>98 \%$, выход $63 \%$.

ИК-спектр: $3450,2980,2230,1470,1380,1375,1145,900 \mathrm{~cm}^{-1}$.

Вычислено, \%: С 60,58; Н 9,15; N 14,13.

Найдено, \%: С 59,14; Н 9,19; N 13,75.

3-Гидрокси-3-метилпентанонитрил (IV). Синтез проводили, как описано выше (III), с той разницей, что вместо ацетона брали бутанон $\left(14,4\right.$ г). При $125-130^{\circ} \mathrm{C}$ (20 мм рт. ст.) перегоняли IV $(10,3$ г), чистота $96 \%$, выход $43 \%$,

ИК-спектр: $3450,2977,2940,2250,1385,1155,1135,935 \mathrm{cм}^{-1}$.

Вычислено, \%: С 63,68; Н 9,80; N 12,38 .

Найдено, \%: С 63,46; Н 9,88; N 12,63.

3 -Гидрокси-4-метилпентанонитрил (V). Синтез проводили, как описано выше (III), беря вместо ацетона 2-метилпропаналь (14,4 г) и добавляя смесь альдегида и ацетонитрила $(30$ г) к смеси КОН в ащетонитриле $(52$ г) в течение 30 мин и продолжая перемешивание еще 2 ч. Получили $\mathrm{V}\left(15,1\right.$ г) с темп, кип. $66-72{ }^{\circ} \mathrm{C}$ (1 мм рт. ст.), чистота $93 \%$, выход $62 \%$, 
ИК-спектр: $3450,2970,2230,1470,1390,1375,1055,1010 \mathrm{~cm}^{-1}$.

Вычислено, \%: С 63,68; Н 9,80; N 12,38.

Найдено, \%: С 64,99; Н 10,62; N 11,09.

3-Метил-2-бутенонитрил (I). В дистилляционной колбе нагревали этиленгликоль (20 г) и $\mathrm{NaOH}(0,2$ г) до растворения. В колбу вливали III $(12,2$ г), соединяли систему с вакуумным насосом и, нагревая колбу при $100 \pm 5^{\circ} \mathrm{C}$, дистиллировали смесь $\left(12,0\right.$ г) с темп. кип. $40-100^{\circ} \mathrm{C}$ (200 мм рт.ст.). После сушки получили I $(10,1$ г) с чистотой $82 \%$, выход $83 \%$.

При повторной перегонке при $135-140^{\circ} \mathrm{C}$ получили I (7,9 г) с чистотой $99 \%$.

ИК-спектр: $2220,1640,1445,1385,1205,810 \mathrm{~cm}^{-1}$.

Вычислено, \%: С 74,03; Н 8,70; N 17,27.

Найдено, \%: С 74,17; Н 8,31; N 17,06.

3-Метил-2-пентенонитрил (II). Дегидратацию проводили, как описано выше (I), исходя из IV (8,6 г). Перегоняли смесь $(8,4$ г) с темп. кип. $50-95^{\circ} \mathrm{C}$ (100 мм рт. ст.). После сушки получили смесь $(6,7$ г) IІа и ІІб, суммарный выход $78 \%$.

При повторной перегонке при $65-70{ }^{\circ} \mathrm{C}$ (40 мм рт.ст.) получили смесь ІІа $(66 \%)$ и ІІб $(31 \%)$.

ИК-спектр: 2220,1640,1470,1450, 1387, 830 см$^{-1}$.

Вычислено, \%: С 75,74; Н 9,54; N 14,72.

Найдено, \%: С 75,11; Н 9,81; N 14,22.

Химические сдвиги ядер ${ }^{13} \mathrm{C}$ синтезированных нитрилов приведены на рисунке.

\section{Выводы}

1. Установлено, что синтез некоторых низших ненасыщенных нитрилов может быть осуществлен в два последовательных этапа: 1) присоединением ацетонитрила, к ацетону, бутанону или 2-метилпропаналю в присутствии $\mathrm{KOH}$ и 2) дегидратацией образовавшихся гидроксинитрилов действием щелочи.

2. Найдены оптимальные условия для обеих реакций с синтезом 3-метил-2-бутенонитрила (выход от теоретического до $56 \%$ ) и 3 -метил-2-пентенонитрила (до $33 \%$ ).

ЛИТЕР А Т Р А

1. Ivanov, C., Angelova, $G$. Synthesis of $\beta$-hydroxynitriles by addition of aceto- or valeronitrile to enolizable ketones. - C. r. Acad. Bulg. Sci., 1966, 19, N 8, $739-742$.

2. Gaudemar-Bardone, F., Gaudemar, M. A convenient preparation and utilization of lithium dialkylamides. - Synthesis, 1979, N 6, 463-465.

3. De Simone, R. S. Process for the preparation of $\alpha$, $\beta$-unsaturated nitriles. U. S. 3 , 960, 923 (1976). - Chem. Abstr., 1976, 85, 123387u.

4. Gokel, G. W., DiBiase, S. A., Lipisko, B. A. Direct synthesis of $\alpha$, $\beta$-unsaturated nitriles from acetonitrile. - Tetrahedron Lett., 1976, N 39, 3495-3496.

5. DiBiase, S. A., Gokel, G. W. A convenient synthesis of aliphatic $\alpha$, $\beta$-unsaturated nitriles from acetonitrile. - Synthesis, 1977, N 9, 629-632.

6. DiBiase, S. A., Lipisko, B. A., Haag, A., Wolak, R. A., Gokel, G. W. Direct synthesis of $\alpha, \beta$-unsaturated nitriles from acetonitrile and carbonyl compounds: survey, crown effects and experimental conditions. - J. Org. Chem., 1979, 44, N 25, $4640-4649$.

7. Inoue, G., Ohshima, N., Hayashi, Y. Processing 3-hydroxyisovaleronitrile. Jap. 7430, 814 (1974). - Chem. Abstr., 1975, 82, 97699p. 
8. Compton, D. A. C., Murphy, W. F., Mantsch, H. H. The I. R. spectra of 3-methyl-2butenenitrile and 3-methyl-3-butenenitrile. - Spectrochim. Acta, 1981, 37A, N 6, $453-455$.

9. Cohen-Adad, R., Michaud, M. Les équilibres liquide-solide du système binaire eaupotasse. - C. r. Acad. Sci., 1956, 242, N 21, 2569-2571.

\section{Институт химии Академии наук Эстонской ССР}

Поступила в редакцию 23/III 1988

Институт химической и биологической химии Академии наук Әстонской ССР

A. MAASALU, T. VÄLIMÄE, Ilme LOIVEKE, Signe TENG, K. LÄÃTS

\section{MÕNEDE HUDROKSU- JA KULLASTUMATA ALIFAATSETE NITRIILIDE SONTEES}

Lähtudes atsetoonist, butanoonist ja 2-metüülpropanaalist on reaktsioonil atsetonitriiliga $\mathrm{KOH}-\mathrm{i}$ manulusel sünteesitud vastavalt 3 -hüdroksü-3-metüülbutaannitriil, 3-hüdroksü-3-metüülpentaannitriil ja 3-hüdroksü-4-metüülpentaannitriil. Hüdroksünitriilide leeliselisel dehüdrateerimisel on saadud 3-metüül-2-buteennitriil ja 3-metüül-2-penteennitriil.

A. MAASALU, T. VALIMÄE, Ilme LOIVEKE, Signe TENG, K. LĂÃTS

\section{SYNTHESIS OF SOME HYDROXY- AND UNSATURATED ALIPHATIC NITRILES}

3-Hydroxy-3-methylbutanenitrile, 3-hydroxy-3-methylpentanenitrile and 3-hydroxy-4methylpentanenitrile were prepared from acetone, butanone and 2-methylpropanale, respectively, by the reaction with acetonitrile in the presence of $\mathrm{KOH}$. The alkali dehydration of hydroxynitriles resulted 3-methyl-2-butenenitrile and 3-methyl-2-pentenenitrile. 